\title{
COMBINING SCIENTIFIC APPROACHES IN BUILDING SCIENCE AND ARCHITECTURAL DESIGN IN ACADEMIA: A CASE STUDY
}

\author{
U. PONT ${ }^{1, *}$, S. SWOBODA ${ }^{2}, A . J O N A S^{2}$, F. WALDMAYER ${ }^{3}$, P. SCHOBER $^{4}$, \\ H. PRIEBERNIG ${ }^{2}$, A. MAHDAVI ${ }^{1}$
}

${ }^{1}$ Department of Building Physics and Building Ecology, TU Wien, Vienna, Austria

${ }^{2}$ Digital Architecture and Planning, TU Wien, Vienna, Austria

${ }^{3}$ Holzforschung Austria, Vienna, Austria

${ }^{4}$ Project and Building Management, TU Wien, Vienna, Austria

*E-mail: ulrich.pont@tuwien.ac.at

\begin{abstract}
A successful coupling of architectural design with multi-aspect building performance assessment is a complex, but necessary requirement for today's building planning- and retrofit-activities. Architects are required to not only possess the vocabulary and basic knowledge in multiple fields, but must also work in collaborative design teams, composed of different domain specialists (e.g., structural engineers and building simulation experts). However, training in collaborative work is rarely provided in academic surroundings. In this contribution, we describe an educational effort toward interdisciplinary work on a specific and clearly defined architectural design task, which strongly necessitates the consideration of performance mandates. The task is the retrofit and redesign of an existing building façade from the 1950s. "Rationalist" buildings of this period often display reasonable functional solutions and good daylight availability, but they have performance shortcomings in other areas. These encompass, for instance, poor thermal performance of the envelope, lack of sufficient indoor environmental control, and unsatisfactory overall appearance. In a combined design studio and project course for building performance modelling, students from different disciplinary backgrounds formed interdisciplinary design teams. These teams worked together on façade retrofit ideas for the aforementioned building, considering both aesthetic aspects and performance issues from the very first design sketch. This led to the development and performance evaluation of a number of original façade retrofit ideas. In addition, the students were asked to devise the building process management. They thus had to consider not only design issues, but practical matters of building construction. The present contribution illustrates the scope, the applied approaches, and the concrete results of this interdisciplinary academic effort.
\end{abstract}

Keywords: façade retrofit, architectural design, interdisciplinary approach, knowledge-based design, parametric design

\section{Introduction}

In recent years the AEC (Architecture-EngineeringConstruction) domain has been exposed to a constant rise of complexity. Amongst other reasons, this is due to i) increasing requirements regarding different performance aspects of buildings, such as indoor comfort, thermal, acoustical, and visual performance of the indoor spaces, or ecological footprint; ii) the change of the fundamental work paradigm in the building planning and delivery process (design teams with a number of domain specialists as consultants instead of one-person responsibilities), iii) the availability of advanced planning tools such as CAD (Computer aided design), BIM (Building Information Modelling) and advanced performance calculation and simulation tools, which on the one hand enable a more comprehensive exploration of the design space, but on the other require in-depth knowledge of the corresponding tools; and iv) increasing time and cost pressure within the building sector. Without doubt, education in the AEC domain has to react on these developments. While some of the mentioned aspects, such as CAD and BIM environments regularly are taught at architecture schools, it has to be stated that current architecture curricula in undergraduate and graduate programmes primarily focus on aspects of building design. Thereby, aspects of building performance, structural stability, cost, and construction processes are, if at all, only considered rudimentary. Needless to say,

This is an open-access article distributed under the terms of the Creative Commons Attribution-NonCommercial 4.0 International License (https://creativecommons.org/licenses/by-nc/4.0/), which permits unrestricted use, distribution, and reproduction in any medium for non-commercial purposes, provided the original author and source are credited, a link to the CC License is provided, and changes - if any - are indicated. 
skills in architectural design are the major target of most educational programmes in architecture. However, alumni often reckon that their education did not sufficiently consider aspects of realism that are typical stumbling blocks in building delivery processes.

The necessity for new approaches in building retrofit can be found in recent research and development efforts. For instance, Pittau et al. (2017) [1] elaborate about the potential of prefabrication for large-scale building energy retrofit and point out that a major argument for prefabrication is the rapidity of the construction process. Khaddaj and Srour [2] illustrate the potential of BIM for the retrofit of existing buildings, but reckon that BIM is still - as a technology - immature for its full adoption in refurbishment projects due to technical, informational, and organizational complications. However, they see BIM as an emerging technology and set of tools for building retrofit in the close future. Different research efforts at the department of Building Physics and Building Ecology at TU Wien, Vienna, Austria, examined new building materials for building retrofit: In a joint research with the Holzforschung Austria, the application potential of vacuum glazing for building retrofit was examined [3]. Thereby, it was found that the replacement of deprecated windows can reduce the heating demand significantly (for Gründerzeit-Buildings the reduction of the heating demand amounted to the same percentage value as the ratio of transparent building components in the façade) $[4,5]$. Another research activity encompassed the application and performance of Aerogel plasters on to historical facades. Thereby, the high potential of such plasters was proven [6-8]. However, due to the material cost of aerogel plaster products, the application currently is only feasible for very special situations in building retrofit. In a recent master thesis, Flegar [9] pointed out the necessity for fast, easy to apply, and economic feasible retrofit technologies for prefabricated buildings from the second half of the 20th century. Such buildings can be found in former Eastern Block countries, former Yugoslavia, but also in other countries of Central Europe. Given the strict geometry regime of the rationalist-inspired architecture of the 1950s to 1980s such retrofit technologies can be applied also to non-prefabricated constructions of similar morphology. Moreover, the importance of the topic is underlined by the EU-funded project Bringing Retrofit Innovation to Application in Public Buildings [10] and the IEA-organized Annex 66 [11].

This contribution describes a TU Wien teaching and research activity pertaining to the relationship between architectural design, performance simulation, and Industry 4.0 concepts (such as intertwining ICT and production processes, digital modelling for prefabrication, etc.). Thereby, interdisciplinary student teams were formed, and asked to work on a typical architectural task in the area of building retrofit. Each team at least encompassed one graduate student of Architecture, and one graduate student of Building Science and Technology. The task was to develop and evaluate the performance of new façade solutions for the envelope retrofit of a prominent existing building in Vienna. The course was a design studio combined with a project course for building performance simulation and focused on the implementation of contemporary state of the art technologies for thermal building retrofitting, such as rapid prototyping, parametric design, and individualized prefabrication. The majority of design concepts developed by the students participating in the course adopted these ideas.

\section{Methodology}

\subsection{Case study building}

The case study building is situated in the city center of Vienna, directly facing the Danube channel and can be

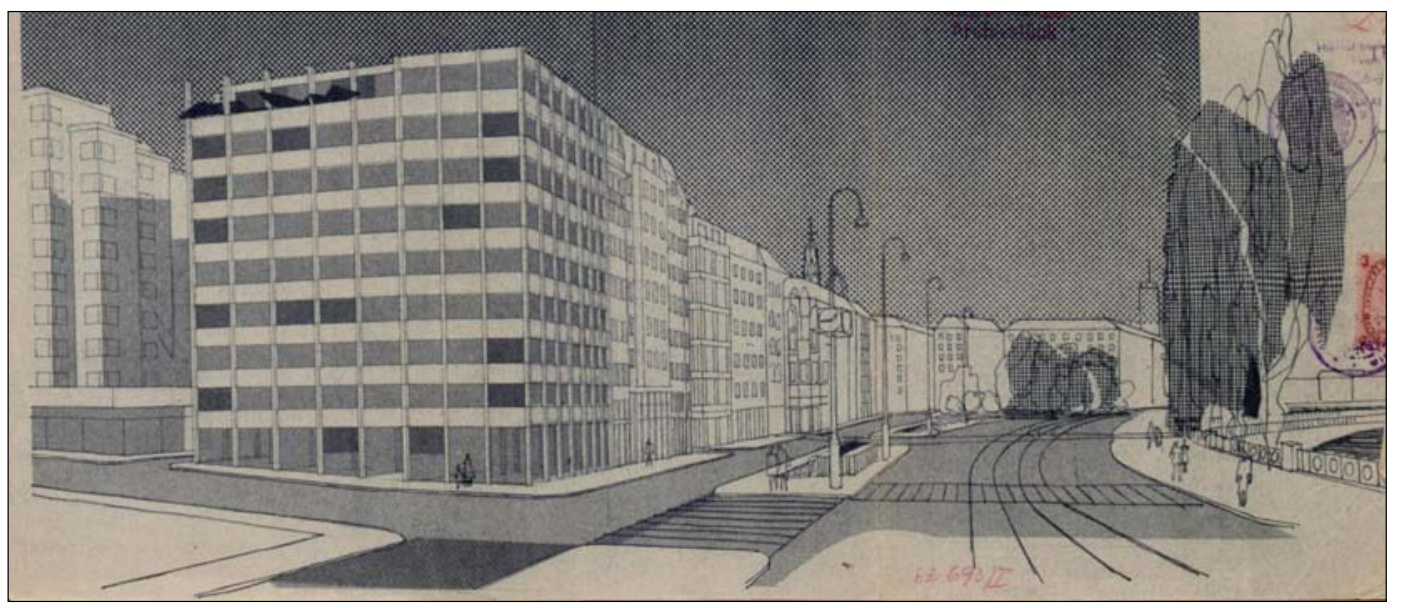

Fig. 1. Perspective draft of the building Schwedenplatz 2 as illustrated in the original plans of 1961 [11] 


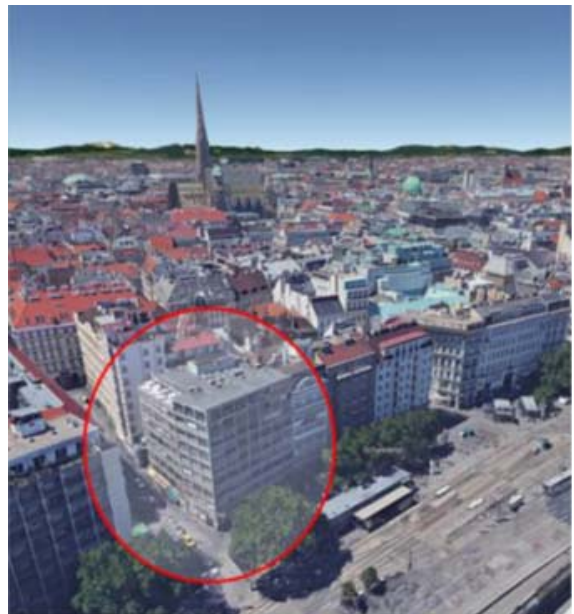

Fig. 2. Bird perspective view of the building Schwedenplatz 2. (Using google earth/ maps, 2017)

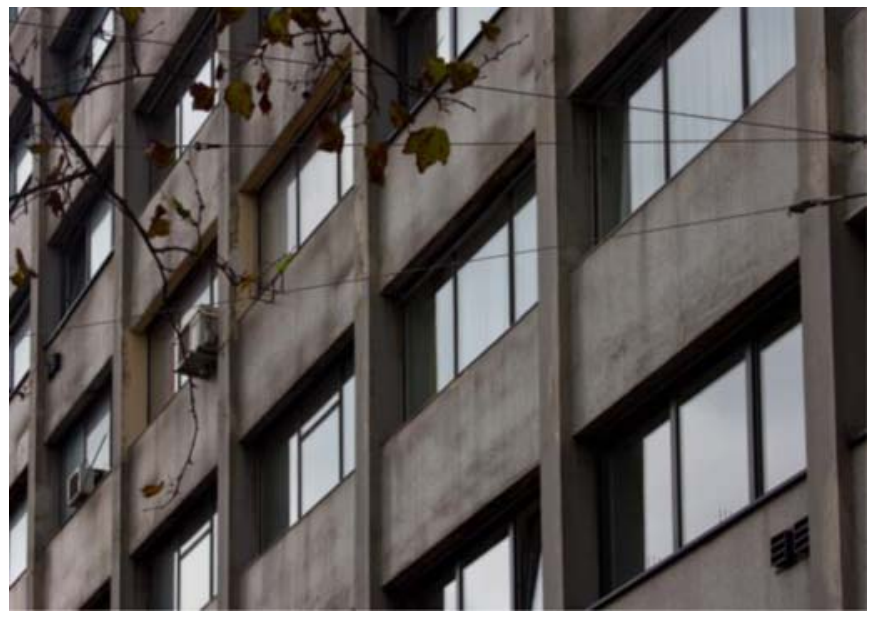

Fig. 3. Façade of the building Schwedenplatz 2 in its today's shape. (Courtesy of L. M. Faurbjerg) considered to be a typical building from the rationalist 1950-1970 period.

Buildings of this period often provide good interior qualities. For instance, they display good daylight availability, given their large window areas. Likewise, functional solutions benefit from simple configurations. However, other properties, such as the thermal performance of the original envelope, do not meet contemporary standards, as - in Austria - provided by the OIB Guideline 6 [12]. Given the strict rectangular and repetitive forms of both ground plan and envelope, such buildings appear to be good candidates for the application of industry 4.0 concepts for retrofit planning, such as parametric design, rapid prototyping and individualized prefabrication of façade elements. The case study building was designed by the architects Wörle and Doskar [13] and was completed in 1961. It is situated in Schwedenplatz within the city center of Vienna and facing the Danube channel. Figure 1 illustrates the building as perspective draft as to be found in the original plans 1961. The building possesses three street facades and features a ground floor area with commercial functions, plus nine upper floors with mixed office and residential usage. Figure 2 provides a 3D-view of the building as of 2017, Fig. 3 shows a part of the façade in its today's shape.

\subsection{Task}

The students had a one semester ( 4 months plus one month finalization time) time period for developing retrofit solutions. In contrast to traditional design studio lectures, the timeframe was split in different phases that required the timely finalization of different tasks as a basis for the subsequent phase. The four phases in the course were Intro-Phase, Draft/Design Phase, Evaluation/Execution Phase, and Reali- zation phase. The Intro-Phase included Teambuilding, Establishment of a Knowledge-base, a set of Impulse lectures, and the generation of first conceptual drafts. In the Draft/Design-Phase these concepts were elaborated to architectural design studies. Aspects that had to be considered in this phase were the aesthetics, the architectural design, and aspects of building physics, material, durability, and maintenance. This phase ended with an intermediate review of the architectural design in form of a presentation-and-poster session. Subsequently the Evaluation/Execution Phase started. In here, the previously developed architectural design had to be elaborated on to the level of construction detail level. Moreover, it included the in-depth analysis of the building's performance after the retrofit with state of the art tools, including overall building performance simulation, thermal bridge evaluation, acoustical and light simulation, and structural analysis. Furthermore, principal aspects of the building delivery process had to be designed. The last phase of the overall course was the Realization phase, which on the one hand included the finalization of a detailed construction timeframe and step-by-step description of the overall building delivery process. Moreover, the student teams were asked to generate a real or virtual mock-up of their design to illustrate the overall functionality of their design. During the Realization phase also the final review session took place. Students had then one more month to conclude all working steps in the project. The final deliverable consisted of a comprehensive documentation of the project itself and its genesis. Beside architectural plans (floor plans, sections, views), the most important details had to be documented in scales from 1:1 to 1:20, dependent on the project. Moreover, a construction phase plan, a comprehensive building performance evaluation (considering energy, thermal, acoustical, visual, and environ- 


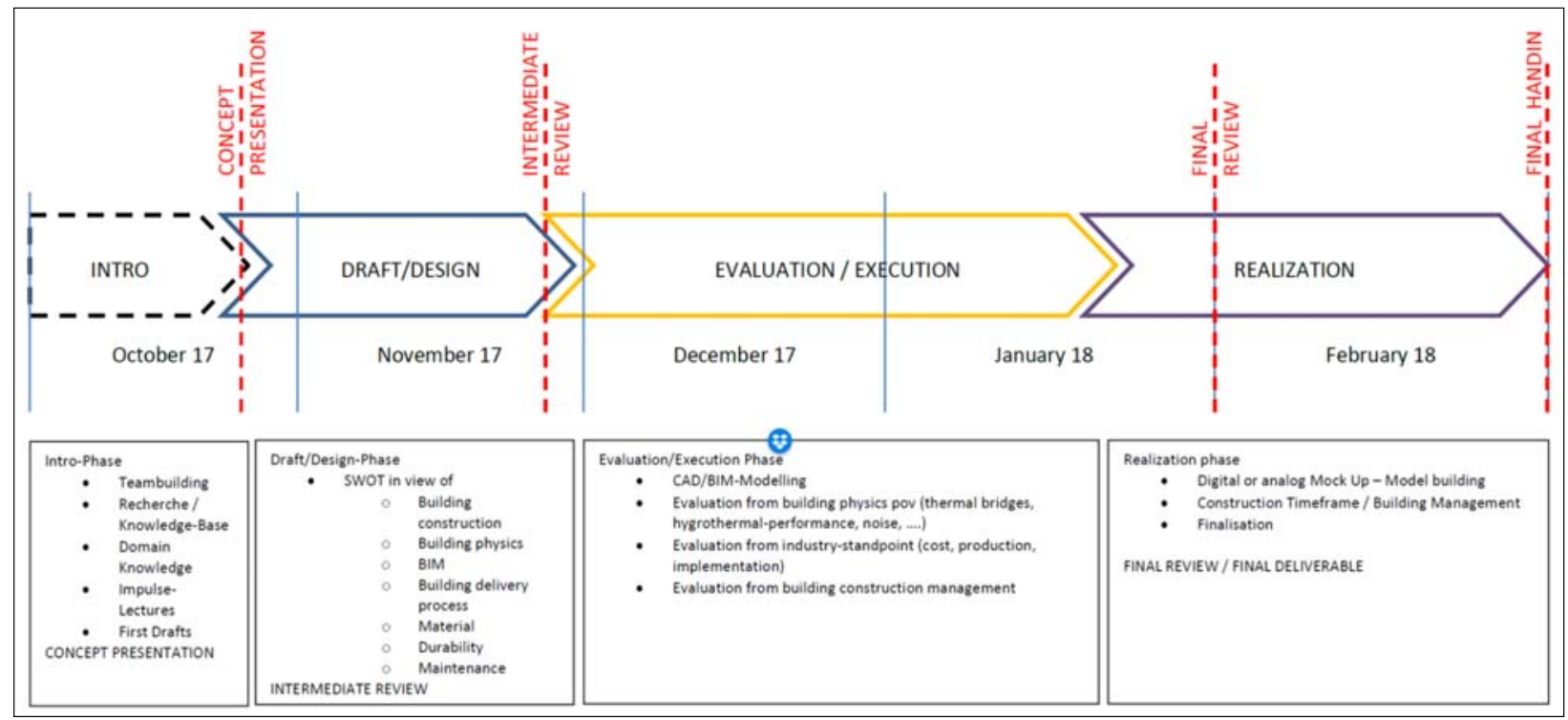

Fig. 4. Time framework of the course

mental aspects), and a BIM-based representation of the design had to be generated and documented.

All designs were repeatedly and continuously subjected to a multidisciplinary review by different domain experts to identify and react to strengths and potential weaknesses. Needless to say, this rigid schedule required the student teams to continuously work together, thus triggering the desired interdisciplinary (and reality-emulating) aspect of the course. Figure 4 illustrates the time framework of the course.

\subsection{Utilized tools}

The different tools used by the student groups encompassed, amongst others, standard drafting, CAD and BIM applications, such as AutoCad [14], Revit [15], ArchiCad [16], and SketchUp [17], building performance evaluation and simulation tools in thermal, visual, and acoustical domain such as ArchiPhysik [18], EnergyPlus [19], Dialux [20], and AnTherm [21] and structural engineering tools such as R-Stab [22]. As in everyday's work practice, students were asked to utilize the tools they had already good command in.

\section{Results and discussion}

Altogether, six interdisciplinary student teams worked in this course. The different retrofit strategies are illustrated in the following subsections.

\subsection{Project Twin Shade}

This project (Fig. 5) suggests the exchange of the existing window sils and windows with floor-to-roof glazing. Depending on the different usages of the building (residential or office) the windows encompass large operable parts, or just small rotation wings for ventilation purposes. Moreover, a versatile steel construction was positioned in front of the building to provide effective external shading devices. These shading devices were intended to be constructed from compressed waste plastic. The steel construction included moveable parts, so that - depending on the side of the building - rotation or curtain-style shift movement is enabled.

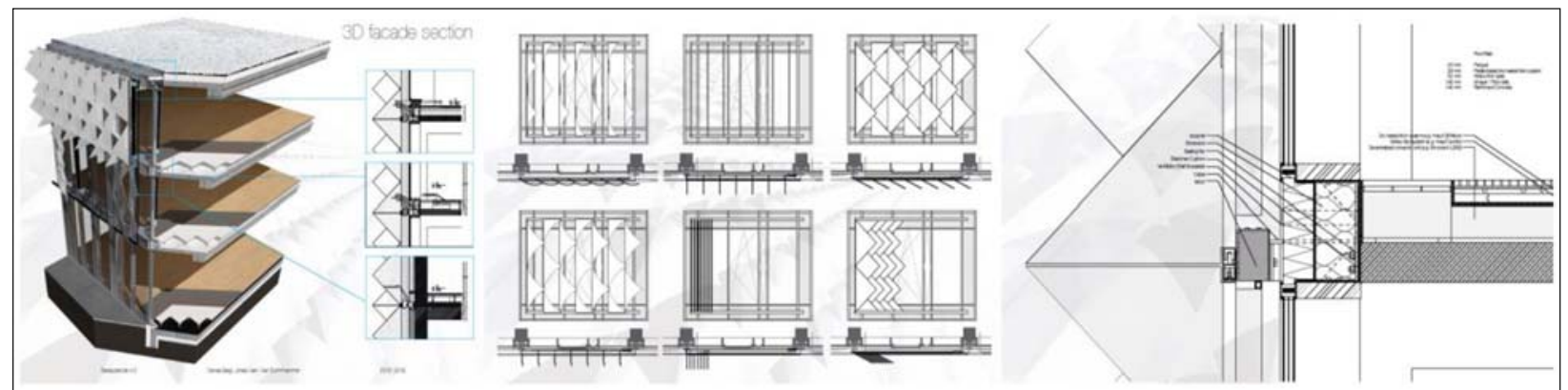

Fig. 5. Project “Twin Shade", section isometry (left), views (center), and detail section (right). (Image courtesy of D. Beigl, J. Marx, and N. Summhammer, participants of the design studio) 


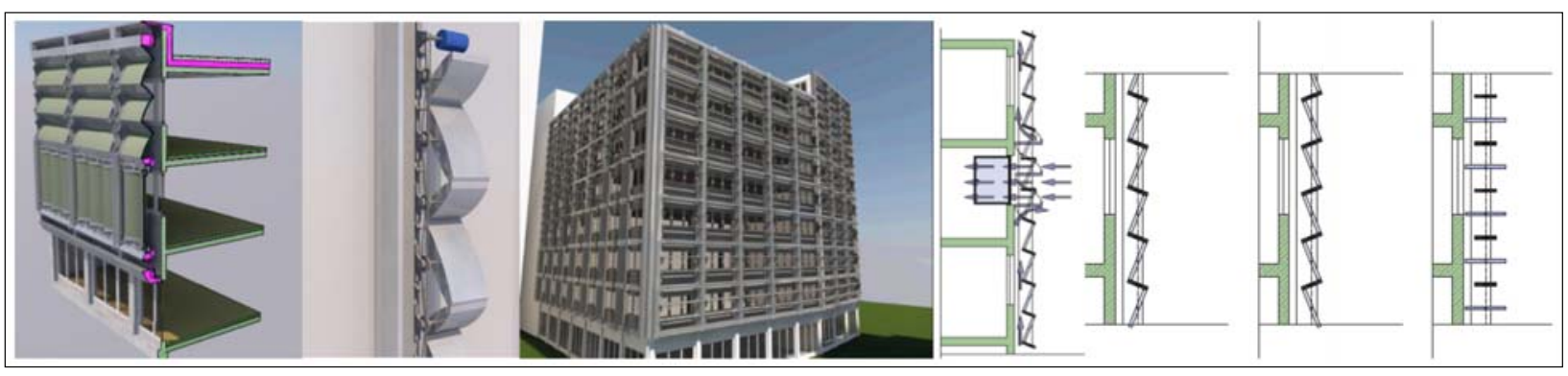

Fig. 6. Project "Magic Meshroom", section isometry (left), functional sketch (left center, far right)), and buildings appearance (right center). (Courtesy of A. K. Chrysochou, G. Holzmann, and P. Korpitsch, participants of the design studio)

\subsection{Project Magic Meshroom}

This project (Fig. 6) suggests a secondary skin in front of the original building envelope. Based on a steel construction, rotating panels allow for different façade settings: Forming a secondary skin improving thermal and acoustical performance for the inhabitants in winter case, and external shading and good ventilation capabilities for the summer case. Given the large amount of moveable components and the non-trivial mechanics behind the system, this project has to be understood as a prototypical approach to an innovative façade.

\subsection{Project Der Diamant}

Der Diamant (Fig. 7) is a project that is based on three design principles, which are i) a high amount of pre- fabrication, ii) performance-based paremetric design, and iii) very short mounting/construction time, with a minimum of impairment of the building's occupants. The parameters generating the different modules included water runoff, aspects of shading, generation of a buffer space, and the module width and height, predefined by the existing building's structural elements axial distance. Based on these parameters, form generation was performed via a grasshopper script [23], considering aspects of factory manufacturing, transport dimensions, fast mounting, and a clean and dry building site.

\subsection{Project Spill-Out Space}

Spill-Out Space (Fig. 8) is a project that utilizes the strict construction grid provided by the origi-

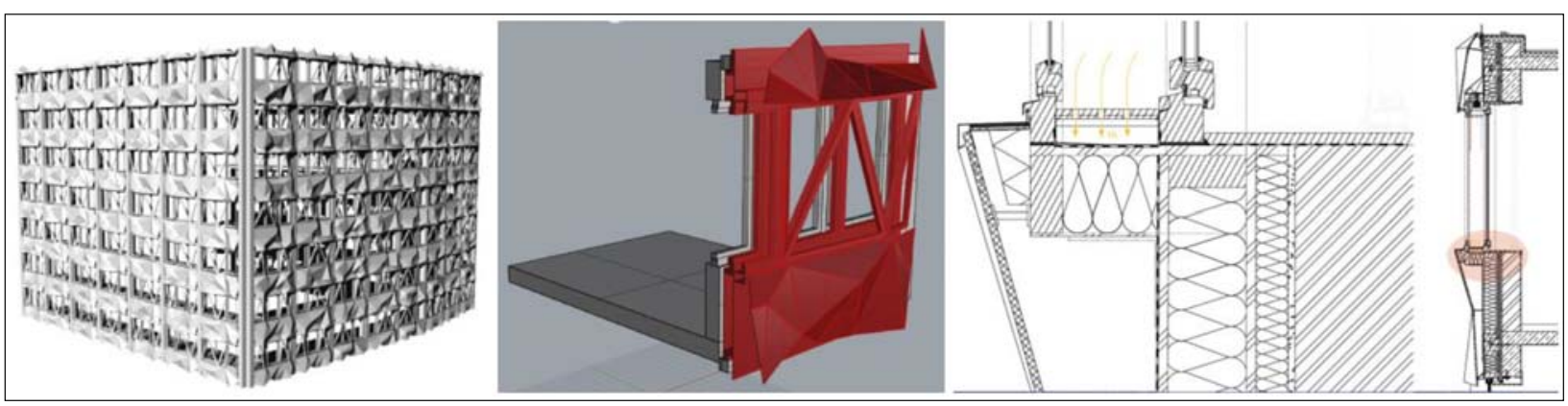

Fig. 7. Project "Der Diamant", isometry (left), system sketch (center), and construction detail (right). (Omage courtesy of M. Pospichal, K. Sperka, and X. X. Zhou, participants of the design studio)

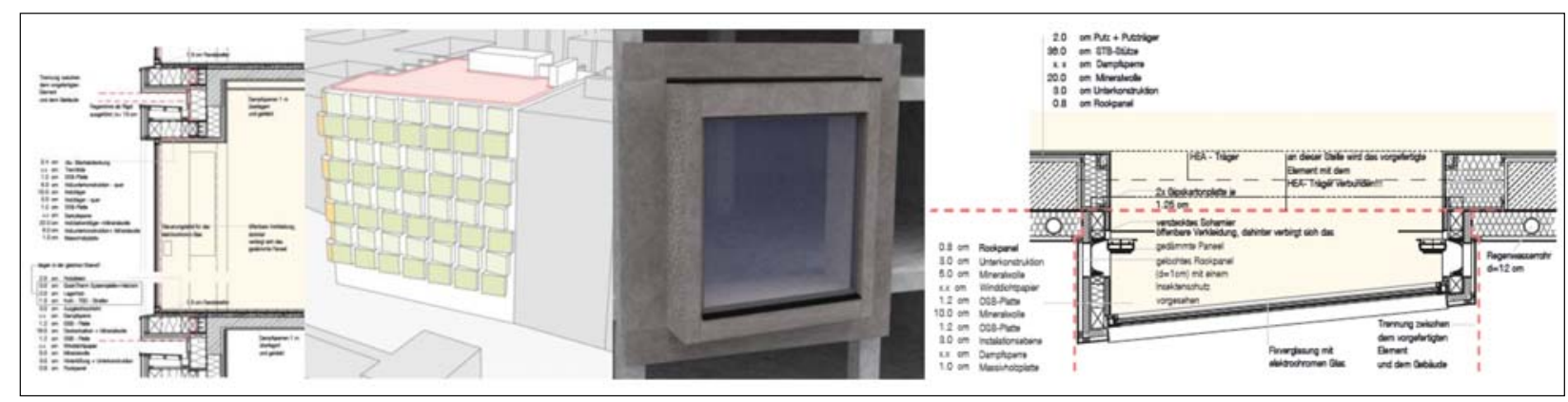

Fig. 8. "Spill-Out-Space", details (outer left and outer right), view (center left), and conceptual illustration (center right). (Image courtesy of C. Casian, T.-I. Rosca, and E. E. Tsankova, participants of the design studio) 


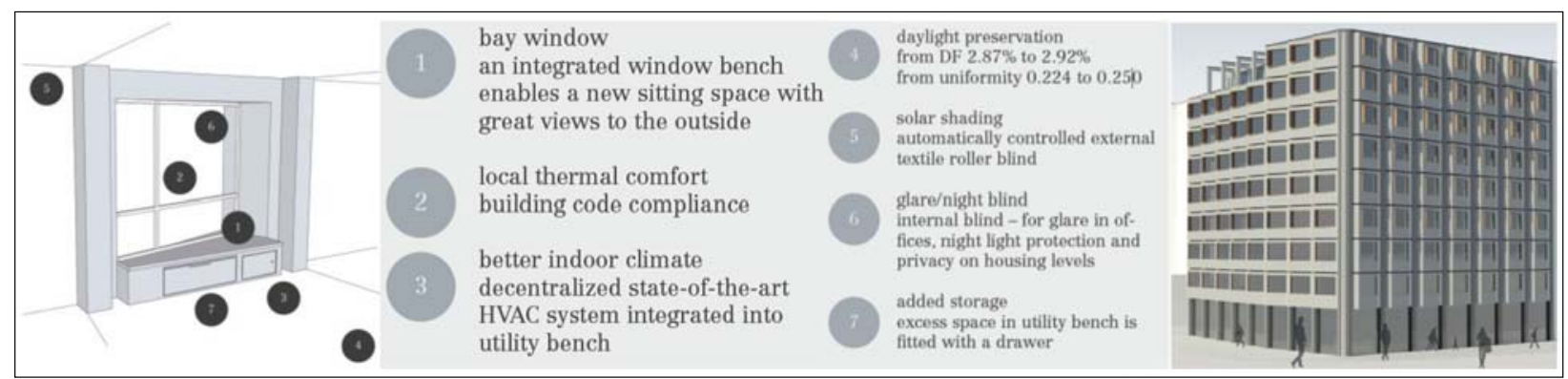

Fig. 9. "Scale project", Conceptual draft (left) and building view (right). (Image courtesy of S. Acar, H. Meiseneder, and L. M. Faurbjerg, participants of the design studio)

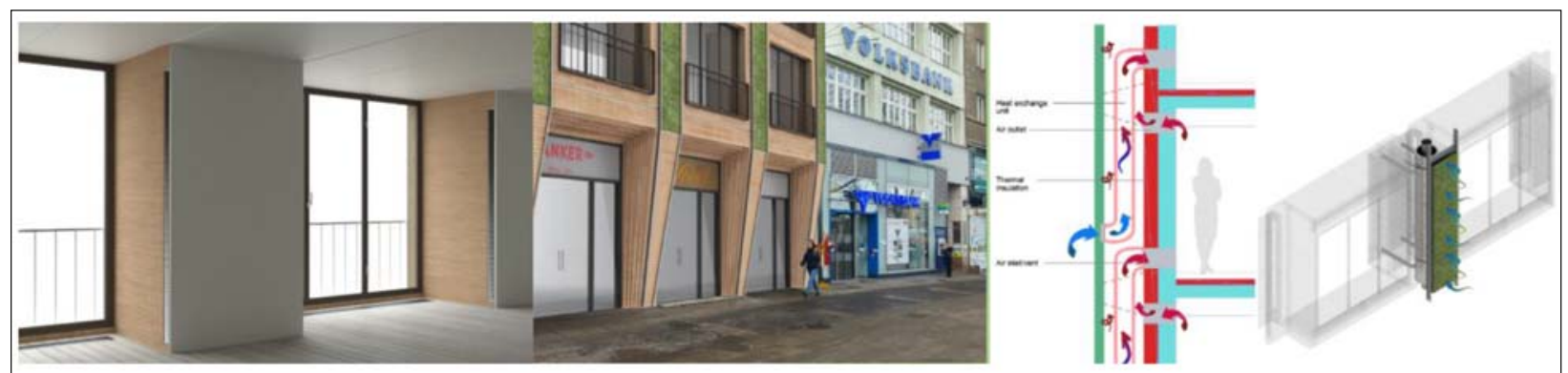

Fig. 10. Project "Green", illustration of a typical indoor space (left), shop facades (center), and ventilation concept schema (right). (Image courtesy of M. Alhayek, Z. Bajka, D. Radulovic, and A. Wadi, participants of the design studio)

nal building. A family of different modules was designed, which aimed at the following aspects: Enlarging the usable space of the existing rooms via offsetting the façade plane slightly to the outside, enabling improved ventilation for spaces that currently do possess cross-ventilation capabilities, decoupling of ventilation openings and visual connection to the outside. Prefabricated, highly isolated modules are attached to the constitutive elements of the building (existing slabs and reinforced-concrete pillars) and not only enlarge the spaces, but also provide larger transparent openings that help to improve the daylight availability. As glazing product electrochromic glass is applied and used to control the radiative compound of energy passing through the window. The prominent corner to Schwedenplatz is additionally utilized for a media façade (for the display of public information, advertisement, or similar).

\subsection{Project Scale}

This project (Fig. 9) established easy-to-mount prefabricated modules that formed a useable window bench for the inside spaces, implementing additional storage space and seating possibilities for the inside space. Another important aspect was to conserve the appearance of the building in terms of the proportion of the building, while at the same time including some barely-to-see adaptations that improve both the user comfort in terms of solar shading and in- door thermal comfort and the winter case KPIs of the building (Key Performance Indicators).

\subsection{Project Green}

This project (Fig. 10) focused on the improvement of the indoor conditions by improving the thermal insulation of the building envelope, integrating a mechanical ventilation system into the new façade and providing vertical vegetation strips on the façade. Moreover, the increasing dimension of the façade is not negated, such as in many other retrofit projects, but rather used to emphasize the appearance of the ground-floor shop facades.

\section{Conclusion}

This contribution shed light on an academic effort in the field of knowledge-based architectural design. Thereby, the term "knowledge-based" refers to the interdisciplinary approach, which was emphasized on the one hand by the interdisciplinary collaboration of students of architects and building science, on the other hand by the different scientific backgrounds of the teachers of the course (building construction, building performance modelling/simulation, $\mathrm{CAD} / \mathrm{BIM}$, building and construction management). One important outcome was the highlighting of both the potential of not-of-the-shelf solutions for retrofit, which are possible due to new technologies (parametric design, rap- 
id prototyping, industry 4.0-principles in terms of prefabrication) and the adaptation potential of rationalist-inspired buildings of the 20th century, even if their status-quo shape might be considered depreciated.

\section{Acknowledgements}

The authors gratefully acknowledge the contribution of the participating students. These include Mahmoud Alhayek, Sezen Acar, Zalán Bajka, Denise Beigl, Cristian Casian, Aikaterini Konstantina Chrysochou, Lise Mansfeldt Faurbjerg, Georg Holzmann, Peter Pavel Korpitsch, Jonas Marx, Helene Meiseneder, Martin Pospichal, Damjan Radulovic, Teodora-Ioana Rosca, Klaus Sperka, Nairi Summhammer, Elitsa Tsankova, Ameer Wadi, and Xian Xiao Zhou. The results of the design studio/project course efforts summarized in this article are currently adapted for a larger booklet, which will be available via the corresponding author of this contribution [24]. This future contribution will encompass details and documentation of all designs that could only be sketched within this contribution to a sufficient extent.

\section{References}

[1] Pittau F., Malighetti L. E., Iannaccone G., Masera, G. (2017), Prefabrication as large-scale efficient strategy for the energy retrofit of the housing stock: An Italian case study. Procedia Engineering, 180, 1160-1169.

[2] Khaddaj M., Srour I. (2016), Using BIM to retrofit existing buildings. Procedia Engineering, 145, 1526-1533.

[3] Pont U., Heiduk E., Schober P., Pichler H., Dolezal F., Proskurnina O., Schuss M., Sustr C., Hohenstein H., Mahdavi A. (2017), VIG-SYS-reno Sondierung von Fenstersystemen mit innovativen Gläsern, speziell Vakuum-Isoliergläsern, zur Gebäudesanierung - Berichte auf Energieund Umweltforschung. Bericht für FFG - Programm Stadt der Zukunft / BMVIT; Final Report, 218 p.

[4] Proskurnina O., Pont U., Schuss M., Sustr C., Heiduk E., Schober P., Mahdavi A. (2016), High-tech solutions for building retrofit: investigation of window systems with vacuum glazing. Applied Mechanics and Materials (invited), Special Volume: Energy Saving and Environmentally Friendly Technologies - Concepts of Sustainable Buildings, 824, 437-444.

[5] Mahdavi A., Schober P., Pont U., Proskurnina O. (2016), VIG-SYS-RENO - Vakuumglas in der Anwendung - Forschungsergebnisse und Ausblick. In: „Fenster-Türen-Treff 2016“, P. Schober, Holzforschung Austria et al. (Eds); pp. 66-82.

[6] Heiduk E., Schuss M., Pont U., Mahdavi A. (2017), AGel$\mathrm{Fa}$ - Entwicklung von strukturierbaren Deckputzsystem auf Aerogel Hochleistungswärmedämmputz für his- torische Gebäudefassaden - Berichte aus Energie- und Umweltforschung; Report for BMVIT / FFG - Haus der Zukunft Plus-Programm; $40 \mathrm{p}$.

[7] Ghazi Wakili K., Stahl T., Heiduk E., Schuss M., Vonbank R., Pont U., Sustr C., Wolosiuk D., Mahdavi A. (2015), High performance aerogel containing plaster for historic buildings with structured façades. Energy Procedia, Proceedings of 6th International Building Physics Conference, IBPC 2015, 324.

[8] Schuss M., Mahdavi A., Pont U., Sustr C., Aien S., Ghazi Wakili K., Stahl T. (2017), Strukturierte Aerogelputze. In: „Bauphysik-Kalender 2017“, 1; N. A. Fouad (Ed.); Ernst \& Sohn Verlag für Architektur und technische Wissenschaften Berlin, Berlin, (eingeladen), ISBN: 9783433031698 pp. $153-175$.

[9] Flegar M. (2018), Performance-based optimization potential of a widely used prefabricated building type: A case study of Zagreb. Master thesis (Master programme Building Science and Technology), supervised by A. Mahdavi and U. Pont. TU Wien.

[10] BRITA in PUBS - Bringing Retrofit Innovation to Appliaction in Public Buildings - EU-project. Available via http://www.brita-in-pubs.eu/ (last accessed June 2018).

[11] IEA Annex 46 - Energy efficient retrofit measures for Government Buildings. Available via http://www. annex46.de (last accessed June 2018).

[12] OIB (ed.). OIB-Richtlinie 6 - Energieeinsparung und Wärmschutz, OIB-330.6-009/15, März 2015. (2015) available via: https://www.oib.or.at/sites/default/files/ richtlinie_6_26.03.15.pdf (last accessed June 2018).

[13] Wörle and Doskar (architects) (1961) - Design Plans of the residential/office building Schwedenplatz 2.

[14] Autodesk AutoCad. https://www.autodesk.com/ (last checked May 2018)

[15] Autodesk Revit https://www.autodesk.com/ (last checked May 2018)

[16] Graphisoft ArchiCAD https://www.graphisoft.com/ (last checked May 2018)

[17] SketchUp https://www.sketchup.com/de (last checked May 2018)

[18] ArchiPhysik https://www.archiphysik.at/ (last checked May 2018)

[19] Department of Energy - EnergyPlus https://energyplus. net/ (last checked May 2018)

[20] Dial - DiaLux/DiaLuxEvo https://www.dial.de/ (last checked May 2018)

[21] AnTherm https://www.antherm.eu/ (last checked May 2018)

[22] R-Stab https://www.dlubal.com/en/products/rstab-beamstructures/what-is-rstab (last checked May 2018)

[23] Grasshopper for Rhino https://www.grasshopper3d.com/ (last checked May 2018)

[24] Pont U. et al. (2018), Fassade 4.0 - Design Studio/Project Course, Winterterm 2017/2018. Department of Building Physics and Building Ecology, TU Wien (To be published). 